\title{
A Reliability Evaluation of Offshore HVDC Grid Configuration Options
}

\author{
Callum MacIver, Keith R. W. Bell, Member, IEEE and Duško P. Nedić
}

\begin{abstract}
This paper details a methodology for investigating the reliability of different offshore grid design options for the connection of offshore wind power to shore. The methodology uses a sequential Monte Carlo based technique that allows investigation of realistic offshore phenomena such as the weather dependency of component repair times. A number of case studies are examined for the connection to shore of a cluster of far offshore wind farms and a cost benefit analysis is performed which compares the capital costs, electrical losses and reliability of each. There is shown to be clear value in options that have inherent redundancy and alternative protection strategies which avoid the use of expensive DC circuit breakers are shown to be potentially viable. It is also found that low probability, high impact faults such as transmission branch failures are a key driver behind overall grid reliability.
\end{abstract}

Index Terms-Reliability modeling, HVDC transmission, offshore wind energy, offshore grid

\section{INTRODUCTION}

$\mathbf{I}_{\mathrm{s}}^{\mathrm{n}}$ the coming years the number, scale and distance from shore of offshore wind farm projects in European waters is expected to grow significantly. The European Wind Energy Association suggests that the installed capacity of offshore wind projects could expand to as much as $150 \mathrm{GW}$ by 2030 [1]. In addition to this there is a growing desire for interconnection between various regions within Europe and the concept of a North Sea offshore grid has been proposed on many occasions, e.g. [2, 3].

Many proposed future offshore wind installations will be very far from shore. Due to reactive charging currents and the need for compensation, several studies have concluded that the use of conventional HVAC subsea transmission for the connection of wind farms becomes increasingly uneconomical as the distance from shore increases and will eventually become practically infeasible beyond a certain distance $[4,5]$. As such it is expected that future offshore grids are likely to be realized as High Voltage Direct Current (HVDC) projects. Voltage Source Converter (VSC) technology is likely to be used for far offshore wind projects due to its inherent black start capability. VSC also delivers a high level of flexibility and power control and so is also preferred for use in multiterminal or meshed offshore grid scenarios over more

This work was supported by EPSRC Grant No.EP/G037728/1, Centre for Doctoral Training in Wind Energy Systems.

The authors are with the Institute for Energy and Environment at the University of Strathclyde, Glasgow, Scotland, UK, G1 1XW (e-mail: callum.maciver@strath.ac.uk) traditional Current Source Converter (CSC) technology that has been widely used in past HVDC point to point interconnection projects [6]. Although some aspects of how to deliver an offshore HVDC grid are becoming clear, there are still a great number of design and technology options available to potential developers and there is a desire to compare the merits of these different options. There are for example, a number of different grid topology options ranging from radial links to shore to meshed grid solutions with multiple transmission paths available to deliver power even in the event of system faults. Monopole or bipole converter configurations can be used, the latter of which provides the ability to retain partial transmission capacity under certain fault conditions. Furthermore there are a number of available protection strategies for offshore HVDC grids that entail the use of different technology options including, potentially, HVDC circuit breakers (DCCBs) which are yet to be realized commercially.

Each of the choices will influence the overall reliability of the grid in terms of energy delivered to shore considering a lifetime of expected fault conditions and each comes at a different cost. Although some studies have considered reliability as part of the investigation of specific future offshore grid scenarios [7-9], no published work has sought to make a direct comparison of the different available design and technology options and their impact on reliability and in turn the financial desirability of offshore projects. This paper looks to address this issue by discussing in detail the various available grid design options (Section II) before identifying various case studies that could be used to deliver power from a specific offshore wind development scenario (Section III). Section IV outlines a novel, weather dependent, Monte Carlo reliability analysis methodology and Sections V and VI present the results and conclusions of analysis carried out on the various grid options.

\section{OFFSHORE GRID OPTIONS}

As stated, offshore networks could be realized using a range of topology options from simple radial connection of wind farms to meshed HVDC networks capable of not only delivering renewable energy generation but also of providing interconnection capacity between regions.

Radial, point-to-point solutions are often the simplest option for single projects and have been used extensively to date for wind farm installations that are isolated, relatively small scale and close to shore. However, as the offshore wind 
industry expands it begins to make sense to introduce greater co-ordination of design and sharing of electrical infrastructure, subsea transmission routes and onshore landing sites. The development of wind farm clusters such as those proposed for UK Round 3 development zones enables such co-ordination.

An extension of this would be the interconnection of multiple wind farm clusters which could act as the first step towards a multi-terminal or meshed offshore HVDC network. It must be noted, however, that implementation of increasingly co-ordinated designs, although technically feasible, would require a number of regulatory, financial and technical barriers to be overcome as discussed in [10].

Protection of potential offshore networks is another area of interest and the choice of protection strategy has a direct relationship to the choice of converter technology. There are a number of different converter options available within the VSC bracket, each delivering different characteristics. Modular multi-level converter (MMC) designs provide a lower loss and smaller footprint design than traditional 2-level and 3-level VSC options making them favorable for offshore application [6, 11]. Half bridge MMC designs are currently available but, in common with other traditional converter designs, have no reverse current blocking capability and so require the use of fast action $\mathrm{DCCBs}$ to avoid voltage collapse in the DC grid. The assumption is often made that DCCBs will be utilized alongside half bridge MMCs to create an offshore network in which each branch is protected in much the same way as existing onshore AC networks however DCCBs have not yet been realized on a commercial scale. Feasible design proposals have been submitted and demonstrated to scale [1214] and it seems likely that DCCBs will become available at the required power levels within a number of years. However, there is still a degree of uncertainty as to their eventual cost with estimates ranging between one sixth and one third of the price of a full HVDC converter unit meaning they are likely to be an expensive solution to use across a full system $[15,16]$ so there is a need for alternative methods to be explored.

One such alternative is to avoid the use of DCCBs and rely on $\mathrm{AC}$ side protection entirely. This form of protection requires that the entire DC grid be temporarily shut down in the event of a DC side fault along with any connected wind farms and due to the relatively slow speed of fault interruption places requirements on the capacity of anti-parallel diodes in the converters [10]. A re-connection process would entail isolating the faulted DC grid section using standard equipment, performing any switching sequences required to re-configure the DC grid to a new optimal operating state and the re-starting of the offshore wind farm output. Such a process is likely to be practically achieved in the order of tens of minutes. As the loss of an entire large DC grid is unacceptable over such a timescale, it is proposed that large networks could be delivered as a set of sectionalized DC grids that are not electrically connected on the DC side under normal operating conditions meaning only one grid section needs to be removed from operation for any given DC side fault. A requirement of such a design is that each grid section should not transmit more power into a region than the designated loss of infeed limit for that region. Grid sections could be re-configured using switching hubs post fault to allow alternative transmission routes to be implemented when required. Such a grid is proposed in the ISLES project [9].

Full bridge MMC designs such as the Alternative Arm converter (AAC) have been proposed with reverse current blocking capability and can thus be used to deliver a DC grid with significantly reduced DC breaker requirement. This functionality is expected to be available at minimal impact to losses and capital expenditure [17].

It has been proposed that full bridge MMCs could be used in conjunction with a reduced number of DCCBs to deliver multi-terminal or meshed DC grids that do not require a disruptive shut down of entire HVDC grid sections [18]. In this scenario a minimum number of DCCBs could be used to effectively split the DC grid into distinct sections post fault, each of which would have a capacity within the loss of infeed limits of any connected onshore AC systems. Upon a DC side fault, the DCCBs would act to isolate the faulted grid subsection, leaving healthy sections unaffected. The fault blocking converters would act to stem the flow of current to the faulted region allowing standard disconnector equipment to isolate the fault within the grid section and thus allow the circuit breakers to re-close and power flow to be re-established through the blocked converters. It is expected that this entire process could be managed in a very short time frame of a few hundred milliseconds [18] such that disruption to the associated AC networks is limited and there is no requirement to shut down offshore wind farms.

\section{CASE StUdies}

To investigate some of the options discussed, various DC grid scenarios are formulated around a clustered offshore development of four $700 \mathrm{MW}$ wind farms. This is similar to prospective early stage developments of UK Round 3 offshore development zones. To evaluate the impact of added redundancy in offshore grids a number of different DC grid configurations are posed, as shown in Fig. 1, starting with the simplest solution of a fully radial option with four direct cable links to shore. The remaining scenarios consider options which make use of shared infrastructure to transmit power down two high power transmission routes. A radial+ option is considered which consists of two separate DC grids each with two wind farms transmitting power down a single transmission path. A multi-terminal DC grid scenario adds a link to the radial+ option, providing a redundant transmission path in the event of fault conditions and creating a single offshore grid. A meshed system is finally considered by adding a second link such that the wind farms are connected in a ring configuration with redundant transmission paths available from each wind farm.

Variations of the multi-terminal grid option are also considered to investigate the feasibility of different protection strategies. One option considers a minimum breakers scenario as described previously which only deploys DCCBs on the link between the two transmission paths while another considers a sectionalized DC grid protected on the AC side, whereby the link between the two main transmission paths is 
switched out under normal operation but can be connected in the event of a post-fault shut-down.
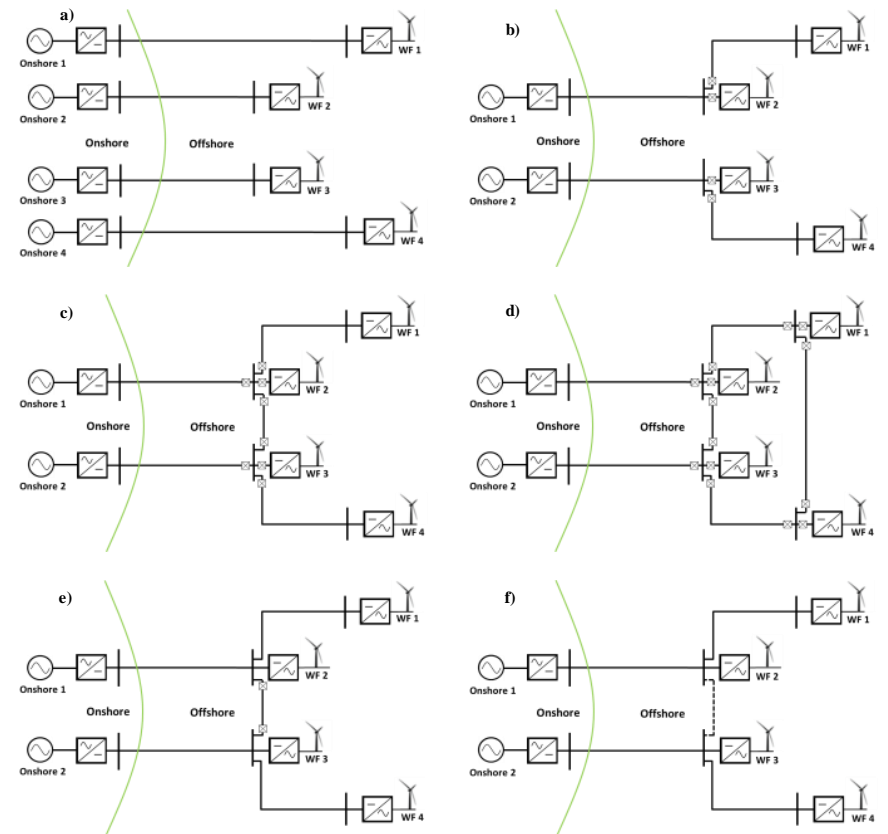

Fig. 1 - Grid Configurations: a) Radial; b) Radial+; c) Multiterminal; d) Meshed; e) Multi-terminal minimum breaker; f) Multi-terminal AC protected

Despite Fig. 1 showing simplified single line representations of the grid options, all the networks are assumed to be configured in a symmetrical monopole configuration with two bundled cables operating at opposite voltage polarity. This also means the actual number of DCCBs required is double that shown in the graphic. Although providing bipolar operation symmetrical monopoles do not provide the inherent redundancy of a true bipole configuration which utilizes a metallic low voltage $(\mathrm{LV})$ return conductor to provide partial transmission capability in the event of poleearth cable faults and converter station faults. A final version of the multi-terminal grid is therefore explored which models bipole operation in the two main transmission paths and assumes 50\% transmission capacity remains in the event of the fault conditions discussed. Some key grid input parameters are outlined in Table I and a summary of all the grid options is given in Table II.

TABLE I

OVERVIEW OF CASE STUdy INPUT VARIABLES

\begin{tabular}{l||l}
\hline DC Voltage Rating & $\pm 320 \mathrm{kV}$ \\
\hline & Radial: \\
& 700MW per route \\
& Radial+, Multi-terminal (all): \\
Transmission Limits & WF1 to WF2 and WF4 to WF3 - 700 MW \\
& WF2 to shore and WF3 to shore - 1400 MW \\
& Meshed: \\
& All routes $-1400 \mathrm{MW}$ \\
\hline \multirow{5}{*}{ Distances } & WF1 to WF2 $-15 \mathrm{~km}$ \\
& WF1 to WF4 $-35 \mathrm{~km}$ \\
& WF2 to WF3 $-20 \mathrm{~km}$ \\
& WF3 to WF4 $-15 \mathrm{~km}$ \\
& WF2 to Shore $-200 \mathrm{~km}$ \\
\hline Cables & WF3 to Shore $-200 \mathrm{~km}$ \\
\hline & 350 MW and $700 \mathrm{MW}$ XLPE \\
\hline
\end{tabular}

TABLE II

Summary of CASE STUdy ATtRibutes

\begin{tabular}{l|c|c|c|c}
\hline \multicolumn{1}{c|}{ Grid Name } & $\begin{array}{c}\text { Grid } \\
\text { Topology }\end{array}$ & $\begin{array}{c}\text { Converter } \\
\text { Technology }\end{array}$ & $\begin{array}{c}\text { Converter } \\
\text { Configuration }\end{array}$ & $\begin{array}{c}\text { Protection } \\
\text { Technology }\end{array}$ \\
\hline \hline Radial & Radial & MMC & Sym. monopole & AC Breakers \\
Radial+ & Three-terminal & MMC & Sym. monopole & DCCBs \\
Multi-terminal & Multi-terminal & MMC & Sym. monopole & DCCBs \\
Min Breaker & Multi-terminal & AAC & Sym. monopole & DCCBs / AAC \\
AC Protected & Multi-terminal & MMC & Sym. monopole & AC Breakers \\
Meshed & Meshed & MMC & Sym. monopole & DCCBs \\
Bipole & Multi-terminal & MMC & Bipole & DCCBs \\
\hline
\end{tabular}

\section{RELIABILITY EVALUATION}

A bespoke reliability software tool has been developed to allow comparison of different DC grid design options in terms of their ability to handle a lifetime of expected fault conditions. The software tool utilises a Sequential Monte Carlo simulation for reliability analysis and much of its functionality is described in [19] although a number of features have since been added. The main advantage of using a sequential analysis is that seasonal variations can be explicitly modelled. Simulated mean wind speed and mean significant wave height (Hs) time series are integrated into the decision making processes within the reliability study allowing results to reflect realistic constraints relating to operation in the offshore environment. Fig. 2 shows the key attributes of the reliability model and the remainder of this section briefly describes each feature whilst expanding on recent developments.

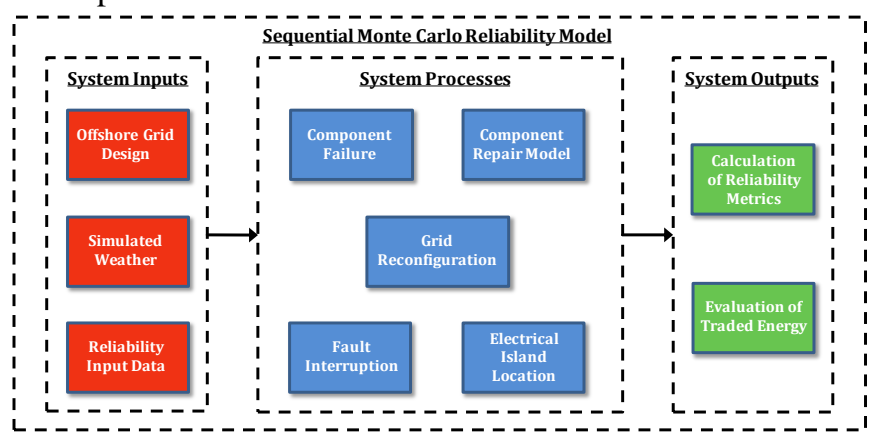

Fig. 2 - Overview of Sequential Monte Carlo Reliability Methodology

\section{A. System Inputs}

\section{1) Network Design}

All offshore networks are designed in $\mathrm{PSS}^{\circledR} \mathrm{E}$ software which allows for easy exportation to the Python based reliability tool for analysis. The offshore network in each scenario is modeled in terms of its main physical components (offshore wind farms, converter transformers, converter stations, transmission branches and circuit breakers or switches/isolators) and a number of key attributes such as voltage ratings, transmission capacity and transmission branch length. Integration within the PSS/E environment allows a common format for subsequent analysis.

\section{2) Weather Data}

This study makes use of data from the FINO 1 offshore Meteorological Mast [20] which has over eight years' worth of concurrent wind speed and wave height data from an offshore site situated in the vicinity of the, Alpha Ventus, German 
offshore wind farm. The wind speed data gathered for use is taken from the highest available measurement height of $80 \mathrm{~m}$ which corresponds to a typical hub height of existing offshore wind installations.

The data has been processed using a Multivariate AutoRegressive approach (MAR) outlined in [21] which captures not only the trends and attributes of the data itself but also the cross-correlations between the wind and wave height output. This is used to generate larger time series of concurrent wind speeds and mean significant wave heights that maintain the characteristics of each dataset, in terms of seasonal trends, mean values and variance, as well as the cross-correlations observed between the wind speed time series and the wave height time series. This study makes use of 100 years' worth of simulated wind speed and wave height time series which are repeated throughout the much longer Monte Carlo simulation process. The resolution of the data is 1 hour and as such this is the resolution used for the entire Monte Carlo process.

Finally a wind speed - wind power curve is required to convert input wind speed time series to wind farm power output. The offshore specific wind speed - wind power curve first developed in [22] is used in this study.

\section{3) Reliability Assumptions}

Faults are considered on a number of key offshore network components and all faults are assumed to cause full outage of that component. Due to the infancy of the industry, there is little published data as to the failure and repair rates for offshore network components although a number of studies have sought to make estimations of likely mean time to fail (MTTF) and mean time to repair (MTTR) figures for major offshore components [8, 23-25]. Three reliability scenarios are developed using the spread of information gathered and through discussion with industry experts which represent best case, central case and worst case reliability scenarios respectively. As experience is gained within the sector it is expected that knowledge gained could be used to refine the reliability scenarios in future. Partly due to lack of appropriate data, faults are not considered on substation components such as switchgear and bus sections. Similarly, despite the fact that auxiliary systems can often be major contributors to component downtime rather than failure of the major components themselves, precise data for auxiliary systems is not publicly available and, as a consequence, these are not explicitly modelled. It is assumed, in any case, that auxiliary system failures are to a great extent factored into the existing published projections for component reliability.

The three reliability scenarios are outlined in Table III and it can be noted that instead of using MTTR values as input to the reliability study, repairs are based on two separate variables as applicable. Each component has a specific repair time which relates to either the number of hours required to physically carry out a repair or the minimum size of the relevant weather window required to carry out a repair as described later. Transformers and transmission cables are also modeled as being subject to a fixed delay which relates to the time period required to procure both a replacement component and a specialist vessel capable of making the repair. The final TTR values and fixed delays used are arrived at through discussion with industry experts and are also broadly reflective of the MTTR values given in the literature.

TABLE III

RELIABILITy INPUT IN Hours For ThreE ScEnARIOS

\begin{tabular}{|c|c|c|c|c|c|c|c|c|c|}
\hline \multirow{3}{*}{ Component } & \multicolumn{3}{|c|}{ Best Case } & \multicolumn{3}{|c|}{ Central Case } & \multicolumn{3}{|c|}{ Worst Case } \\
\hline & \multirow{2}{*}{ MTTF } & \multicolumn{2}{|c|}{ Repair } & \multirow{2}{*}{ MTTF } & \multicolumn{2}{|c|}{ Repair } & \multirow{2}{*}{ MTTF } & \multicolumn{2}{|c|}{ Repair } \\
\hline & & Fixed & TTR & & Fixed & TTR & & Fixed & TTI \\
\hline On. Converter & 17532 & - & 3 & 7200 & . & 6 & 2880 & - & 24 \\
\hline Off. Converter & 17532 & . & 3 & 7200 & - & 6 & 2880 & - & 24 \\
\hline On. Transformer & 876600 & 1440 & 48 & 438300 & 2160 & 72 & 350640 & 2880 & 96 \\
\hline Off. Transformer & 438300 & 1440 & 96 & 350640 & 2880 & 120 & 262980 & 4320 & 144 \\
\hline $\begin{array}{c}\text { Transmission } \\
\text { Branch }\end{array}$ & $438300^{\circ}$ & 1440 & 120 & $219150^{*}$ & 2160 & 144 & 109575* & 2880 & 168 \\
\hline DCCB & 525960 & - & 3 & 219150 & . & 6 & 131490 & . & 24 \\
\hline
\end{tabular}

\section{B. Monte Carlo Processes}

\section{1) Failure Modeling}

At the beginning of the process and after all repairs, system components must be given a value for expected time to fail, i.e. to change from the in service state to the out of service state due to a forced outage. Components are assumed to operate under constant failure rate and time to fail (TTF) values are therefore based on exponentially distributed randomised values which converge on published component MTTF data. The process used to generate failure times for each component is shown in equation (1), where $\mathrm{R}$ is a uniformly distributed randomly generated number between 0 and $1[26]$ :

$$
T T F=-M T T F * \ln (R)
$$

\section{2) Repair Modeling}

One of the key reasons for choosing a sequential methodology is that it intrinsically allows consideration of seasonal impacts on the ability to repair components. Repairs are split into a number of categories and repair times calculated based upon realistic weather based criteria as outlined in Table IV and explained below.

TABLE IV

REPAIR MOdel CATEgories

\begin{tabular}{c|c|c|c|c}
\hline & $\begin{array}{c}\text { Major } \\
\text { Offshore }\end{array}$ & $\begin{array}{c}\text { Minor } \\
\text { Offshore }\end{array}$ & $\begin{array}{c}\text { Major } \\
\text { Onshore }\end{array}$ & $\begin{array}{c}\text { Minor } \\
\text { Onshore }\end{array}$ \\
\hline \hline Components & $\begin{array}{c}\text { cables, } \\
\text { transformers }\end{array}$ & $\begin{array}{c}\text { converters, } \\
\text { DC breakers }\end{array}$ & transformers & converters \\
\hline $\begin{array}{c}\text { Weather } \\
\text { Window }\end{array}$ & continuous & non - continuous & - & - \\
\hline $\begin{array}{c}\text { Weather } \\
\text { Criteria }\end{array}$ & $\begin{array}{c}\mathrm{Hs}<1.5 \mathrm{~m}^{*} \\
\mathrm{Hs}<2 \mathrm{~m}^{* *}\end{array}$ & $\mathrm{Hs}<1.5 \mathrm{~m}$ & - & - \\
\hline $\begin{array}{c}\text { Procurement } \\
\text { Delay }\end{array}$ & fixed & - & fixed & - \\
\hline \begin{tabular}{c} 
Shift Length \\
\hline
\end{tabular} & $15 \mathrm{hrs}$ & $15 \mathrm{hrs}$ & $12 \mathrm{hrs}$ & $12 \mathrm{hrs}$ \\
\hline
\end{tabular}

$\mathrm{H}_{\mathrm{s}}=$ mean significant wave height * cable faults ** transformer faults

Major offshore repairs are taken to be repairs which require the procurement of a specialist vessel and/or a replacement component. Transformer replacements are likely to require use of a heavy lift vessel (HLV) [27] whereas cable repairs require a specialist vessel or modified vessel with the appropriate equipment (replacement cable section, jointing house, cranes and winches) to carry out the repair [28]. It is considered that repair time for these components is significantly driven by both the time required to procure the appropriate vessel and 
replacement component and the weather constraints related to the actual repair process. Given this, a fixed time period is associated with each repair under this category which represents the minimum time required to carry out all preliminary work up to the point of carrying out the repair. After that point, it is determined that major repair operations require a fixed weather window under which to perform the entire repair operation which is likely to be in the order of several days.

For cable repairs, relatively calm seas are required to carry out the repair process which requires locating the two damaged ends of the original cable and jointing each end to a new cable section. Any periods of rough weather could lead to the loss of work already carried out so a maximum $1.5 \mathrm{~m}$ wave height criterion is applied which is equal to the restrictions in place for gaining safe access to offshore platforms [27]. For transformer repairs it is assumed that either an HLV or a large field support vessel (FSV) with suitable crane is used to perform the repair. These vessels operate to a less strict maximum safe wave height criteria set at $2 \mathrm{~m}$ [27].

Perfect forecasting is assumed and a suitable weather window is determined through a search of the Hs time series from the beginning of the first repair personnel shift after the fixed delay period. The repair time is determined once a single weather window is found greater than or equal in size to the time required to carry out the entire repair. Travel times to and from the repair site are included in the minimum repair window duration.

Minor offshore repairs are assumed to have less stringent repair criteria. For relatively near shore operations a standard crew transport vessel (CTV) is likely to be used to transfer the required personnel to the repair site. For maintenance much further than $70 \mathrm{~km}$ offshore it is likely that helicopter access would be required due to the relatively slow transit time of CTVs or that a permanently manned offshore maintenance hub would be constructed to allow quicker access to offshore platforms [27]. The ability to perform such repairs is again weather dependent and relies on the ability of personnel to safely transfer from the CTV to the offshore platform. The industry standard criteria for safe transfer states that the mean significant wave height should not exceed $1.5 \mathrm{~m}$. If helicopter access is assumed the safety criteria would be based on visibility and wind speed as opposed to significant wave height. From discussions with industry experts it is found that there is anecdotal evidence of a high degree of crossover between periods of CTV and helicopter access restrictions. Visibility data for use in conjunction with wind speed and wave height data is lacking so modelling helicopter based repairs in detail is difficult. As such, CTV wave height restrictions are applied in this study.

The methodology for minor offshore repairs again assumes perfect forecasting of wave conditions and looks forward into the wave height time series associated with the next available working day and determines the largest available weather window, within working hours, in which wave heights are consecutively below the access threshold. If that weather window minus the transfer time to get to the fault is above a minimum threshold of two hours then it is assumed work is carried out on that day and banked towards the total required repair time. The process repeats through each working day until enough hours have been banked and the total time from point of failure to point of repair is calculated. If two weather windows are available within a single shift then it is assumed that the maintenance team would make use of the largest single weather window.

Onshore repairs relate to onshore converter and transformer failures and are not considered to be influenced by weather conditions. The same process as described for minor offshore repairs is used but with no restrictions to the ability to carry out the repair. The repair time is determined once enough hours have been worked during each shift after the point of failure to complete the repair. In the case of onshore transformer repairs, a fixed delay period is maintained to account for the time required to procure the replacement component and organize the repair.

\section{3) Fault Handling}

In the event of 'active' faults, fault current interruption is assumed to be successfully achieved using the nearest available DCCBs or, in cases without DCCBs, through actions taken at the terminals of the DC grid either through use of AC side protection or the use of fault blocking converters. Network re-configuration is then assumed to occur such that the faulted component is isolated by the opening of appropriate isolators or circuit breakers, whichever succeed in minimising the number of components, other than the faulted one, that are also isolated. A recursive algorithm is used to identify the isolated grid sections which steps through the network from the component that has failed until the nearest circuit breakers or isolators on either side are reached. This works by running through each branch that is adjacent to the fault, only stopping once either a circuit breaker or isolator is reached or the end of the line is reached. All buses that have been passed on the way are removed from service along with any connecting branches

As explained in [19] the tool also has the ability to optimize the reconfiguration of grid designs that have multiple switching options available in the event of fault situations. However, no such grids are examined in this paper.

\section{4) Identification of Electrical Islands}

Once a fault has occurred and the fault handling and grid reconfiguration codes have completed the task of switching out all affected components and re-configuring the grid if necessary, a further function is applied in order to understand the new state of the system. This function acts to locate any distinct and valid electrical islands that are functional in the system. It uses the same recursive technique as the fault handling algorithm to step through the system from each conceivable start point. This time there is no stop criterion other than the fact that the function will not continue if it reaches a bus or branch that has been removed from service and the function is allowed to run through the entire system until all buses connected to the start point have been identified. If a wind farm converter bus and an onshore converter bus or two onshore converter buses are found to be part of the same island then this is a valid electrical island which allows either transmission of wind power or cross regional trading. The function continues until all such islands have been located. Any remaining buses which are not 
identified in this process are removed from service allowing identification of any wind farms unable to transmit power.

\section{System Outputs}

To evaluate system reliability the level of undelivered energy can be calculated in the course of the Monte Carlo simulation each time a system state is entered under which one or more wind farms are disconnected or if any transmission capacity is disconnected. The undelivered energy due to wind farm disconnection is calculated for each hour that the system is in that state by multiplying the corresponding values from the simulated mean wind speed time series by a per unit conversion factor derived from the input wind speed-wind power curve and the total capacity of disconnected wind farms on the system. A calculation is also made of the energy lost through curtailment due to disconnected transmission capacity if the system power output minus expected losses at any hour is higher than the remaining transmission capacity.

Although none of the case studies examined in this paper has the option of cross-border trading, the reliability tool is also capable of calculating the level of both firm and flexible trading capacity for each hour as explained in [19].

\section{Electrical Loss Modelling}

To allow for a comprehensive comparison between the merits of different grid options the level of expected losses is calculated for each. A full electrical loss model requires detailed system modelling and an appropriate software package and is not efficient as an online calculation within the Monte Carlo analysis. An offline process is instead used to estimate the average level of expected losses and the results are used within the Monte Carlo simulation such that losses are accounted for in the final results. This is done by calculating the copper losses in subsea cables, from $P_{\text {loss }}=I^{2} R$, and the expected percentage losses accrued at converter stations and DCCBs. The assumptions, shown in Table V, used to determine system losses are derived from published figures in $[15,29]$ assuming greater relative efficiency in higher rated components. It is also assumed that losses in AAC's are 15\% higher than standard MMC's in line with [17].

TABLE V

ELECTRICAL LOSS PARAMETERS

\begin{tabular}{c|c|c}
\hline \multirow{2}{*}{ Component } & \multicolumn{2}{|c}{ Electrical Losses } \\
\cline { 2 - 3 } & $\mathbf{7 0 0 M W}$ & $\mathbf{1 4 0 0 M W}$ \\
\hline \hline MMC & $1 \%$ & $0.9 \%$ \\
\hline AAC & $1.15 \%$ & $1.035 \%$ \\
\hline DCCB & $0.01 \%$ & $0.08 \%$ \\
\hline Transmission Cable & $0.02 \Omega$ & $0.01 \Omega$ \\
\hline
\end{tabular}

The level of electrical losses on a network varies with the amount of current in the system with proportionally higher losses as the grid approaches full utilization. To estimate average losses, the wind power frequency distribution of the input mean wind speed time series is used which gives the frequency of time spent in each of a range of power output bins. By considering how power flows are likely to be controlled in the system, for any given level of generation the expected level of electrical losses at each element in the network can be determined using the stated loss parameters. Given knowledge of the amount of time spent at each generating level and the level of expected losses associated with each level, a calculation of the average annual electrical losses expected to occur on an intact network is made. Variation in the level of losses between the intact state and failure states is also accounted for but is found to have negligible influence. The total level of undelivered energy calculated in the reliability study is therefore made with reference to the total level of generated energy that enters the grid minus the average losses associated with that grid.

\section{E. Cost Modelling}

An evaluation of the project costs associated with each grid option is also made, allowing the value of energy delivered through each grid to be compared to the cost of delivering that energy. Published capital cost estimations relating to offshore infrastructure are given in [5] and [30] and form the basis of the cost analysis in this study. Where costs are given for component ratings unequal to the test case studies examined, costs are inferred from the nearest applicable values through linear interpolation.

As discussed, DCCBs have not yet been delivered commercially and as such there is no cost data available. An estimate is therefore required based on knowledge of the proposed design solutions. A hybrid option using a power electronic branch as the means of current interruption, as proposed in [12], is one of the most advanced design options. It is assumed in [15] that an upper limit on the cost of DCCBs is one sixth of a full VSC converter station, given the need to handle only the pole-ground voltage of the converter output, and that is the assumption used in this study.

As well as exploring the capital costs of the proposed grid options, a consideration has also been made of the operational costs in terms of the O\&M costs associated with carrying out component repairs. Figures relating to the day rates of hiring vessels, personnel costs and repair cost of components are used to calculate the cost of each repair as it happens using data gathered from $[5,27,31]$. The O\&M costs were found to be negligible in relation to the project capital expenditure (CAPEX), however, so are included in the results but not explored in further detail.

\section{RESULTS AND DISCUSSION}

\section{A. Comparison of Grid Options}

The headline results from the reliability analysis are presented in Table VI which gives the level of average annual expected electrical losses associated with each grid as well as the expected level of annual undelivered energy for each of the three reliability scenarios investigated. The electrical losses are given as a percentage of the total wind energy delivered to the offshore grid from each of the connected wind farms for an intact network; the undelivered energy is expressed as a percentage of the total energy that would be delivered to shore in a year given intact operation. The stop criterion used for the Monte Carlo simulation is outlined in [32] and [33] and ensures the final expected undelivered energy results are accurate to within $\pm 1 \%$ of the true mean. 
TABLE VI

RELIABILITY ANALYSIS RESULTS

\begin{tabular}{l|c|c|c|c}
\hline \multirow{2}{*}{} & \multirow{2}{*}{$\begin{array}{c}\text { Electrical } \\
\text { Losses }\end{array}$} & \multicolumn{3}{|c}{ Undelivered Energy } \\
\cline { 3 - 5 } & & Best Case & $\begin{array}{c}\text { Central } \\
\text { Case }\end{array}$ & $\begin{array}{c}\text { Worst } \\
\text { Case }\end{array}$ \\
\hline \hline Radial & $2.85 \%$ & $1.92 \%$ & $5.34 \%$ & $15.29 \%$ \\
\hline Radial+ & $2.80 \%$ & $1.96 \%$ & $5.48 \%$ & $15.41 \%$ \\
\hline Multi-terminal & $2.80 \%$ & $1.31 \%$ & $3.65 \%$ & $10.81 \%$ \\
\hline Min Breaker & $3.07 \%$ & $1.30 \%$ & $3.54 \%$ & $10.53 \%$ \\
\hline AC Protected & $2.79 \%$ & $1.31 \%$ & $3.58 \%$ & $10.59 \%$ \\
\hline Meshed & $2.79 \%$ & $1.27 \%$ & $3.46 \%$ & $10.38 \%$ \\
\hline Bipole & $2.80 \%$ & $0.74 \%$ & $2.14 \%$ & $7.05 \%$ \\
\hline
\end{tabular}

The losses are broadly similar for each of the case studies although higher losses are seen in the simple radial solution due to the increased number of converter stations and cables used. The losses associated with the minimum breaker grid are also higher due to the assumption that losses in AAC converters would be $15 \%$ higher than standard MMC converters.

In terms of undelivered energy, the value of added redundancy and alternative transmission paths is apparent with the two radial solutions susceptible to significantly higher levels of energy curtailment than the multi-terminal and meshed options. It is apparent that the three options which utilise a multi-terminal solution via different protection strategies have similar performance with the assumed method of using DCCBs actually giving slightly higher levels of undelivered energy due to the introduction of the DCCBs themselves adding an additional layer of components that are susceptible to faults. The minimum breaker option reduces this burden and the $\mathrm{AC}$ protected option removes it completely. This option, however, is subject to short periods, modelled as one hour, after each fault in which an entire grid section is out of service and the impact of this in terms of additional energy curtailment is seen in that the minimum breakers option has the best reliability performance of the three on average.

Adding the additional complexity of the meshed option further reduces the amount of curtailed energy. However, in this case study the impact is relatively small. If the wind farms were more dispersed or the system more complex, the value of a meshed grid would likely be more apparent although the cost of implementing it would also increase. The results for the Bipole grid option, however, show dramatically improved reliability performance compared with the symmetrical monopole grid solutions with undelivered energy reduced to $60-70 \%$ of the best performing monopole solutions. This highlights the vulnerability of the symmetrical monopole configuration to fault conditions even when an alternative transmission path is present in the system.

The capital cost of delivering each of the grid options is shown in Fig. 3 along with the percentage of total generated energy that is delivered to shore in each for the three reliability scenarios when electrical losses and undelivered energy are accounted for. There is a large degree of deviation in the expected capital cost of the different grid options. The purely radial option has two extra converters and significant extra circuit length compared with the radial+ option which, through co-ordination of design and sharing of infrastructure, is around
$£ 480$ million cheaper in terms of CAPEX and delivers broadly comparable levels of delivered energy.

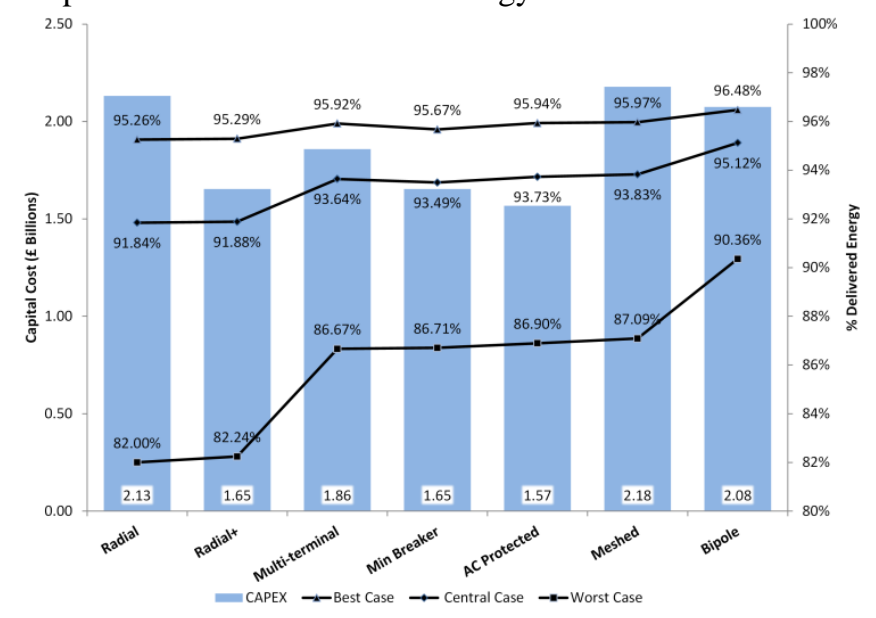

Fig. 3 - CAPEX vs Delivered Energy under Different Reliability Scenarios

The multi-terminal option requires extra cabling and the introduction of a large number of DCCBs and as such has a significantly higher CAPEX than the radial+ solution although this is traded against a significantly higher total delivered energy, especially in the central and worst case reliability scenarios. The minimum breaker and $\mathrm{AC}$ protected grid options have reduced overall cost in comparison to the multiterminal grid through a reduction in the required number of DCCBs from sixteen to four and zero respectively. It is assumed that the AAC converters of the minimum breaker solution have no extra costs over standard half bridge MMC converters [17]. As highlighted in Table VI, there is little difference in the level of delivered energy between these grid options although the slightly increased electrical losses in the AAC converters is seen to have a discernible influence in the best case and central case reliability scenarios.

The meshed DC grid option is shown to have the highest CAPEX due to increased DCCB requirement, the need to rate all circuits for high transmission capacity and the addition of another cable route. In this design, all transmission branches are rated to carry the full capacity of two offshore wind farms to allow uninhibited re-routing of power under all but the rarest overlapping fault scenarios. Given that the output of wind farms rarely reaches full capacity, a more detailed study would seek to optimise the ratings of each branch based on the cost trade-offs relating to CAPEX, losses and curtailed energy. As suggested, in this case study, the relative gains in terms of total delivered energy of the meshed grid option in comparison to the multi-terminal grid options are small.

The Bipole grid option is also considered to have a relatively high CAPEX as there are extra costs associated with the requirement for specially designed transformers capable of withstanding the DC voltage offset introduced in the bipole configuration [34] as well as the need for an additional LV return cable in the transmission route to act as the return path in post fault operation. Without detailed published estimates for either of these implications it has been assumed that the added costs of the bipole configuration are a $10 \%$ increase in the cost of the converter station and that the LV bipole return cables are $50 \%$ of the cost of standard high voltage cables given reduced insulation requirements. The need to bury the 
bipole cables apart to minimise the chance of pole to pole faults occurring is also considered. The benefits of higher up front spending are clearly apparent for the bipole grid option, however, with significantly higher levels of delivered energy on average.

The trade-off between CAPEX and delivered energy is presented here by calculating the net present value (NPV) of each of the grid options which allows a direct comparison between each option and enables an informed design choice. This is done by estimating the value of expected annual energy delivered in each grid by assuming that each megawatt hour of wind energy has a value of $£ 150$. This is equal to the maximum strike price expected to be awarded to GB wind farm operators in 2016/17 [35]. The annual value delivered is discounted at a standard rate of $6 \%$ over an anticipated 25 year project lifespan to give the total project value of each grid option. The calculated projects costs are deducted from the total project value to give the NPV of each grid option and the results are shown in Fig. 4. A more complete analysis might also consider the cost of energy to replace that which is curtailed, the impact on total social welfare or the direct remuneration of the offshore transmission owner. However, these depend on a range of assumptions that are beyond the scope of the present paper. Issues that might influence the financial impacts on different industry actors are discussed in [10]. These include the different incentives on wind farm developers, offshore transmission owners and the system operator and the difficulty of achieving a coordinated offshore network design to connect a number of wind farms that have different owners and different development timescales.

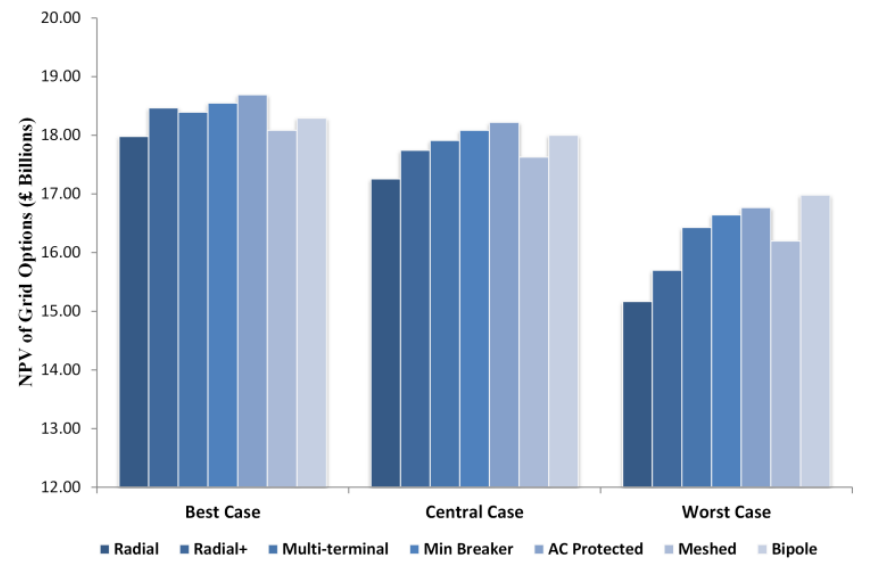

Fig. 4 - NPV of Grid Options

The value of redundancy in offshore grids is shown to be heavily dependent on the reliability input assumptions meaning that under the best case reliability scenario there is little difference in the NPV of each of the grid options with the low cost radial+ option giving comparable value for money to more fault resilient multi-terminal and bipole configurations.

As component reliability reduces, the NPV of the radial grids drops off in comparison to other options. The low cost AC protected multi-terminal option which avoids the use of DC breakers is found to be the best value for money given best case and central case reliability scenarios. This suggests it is a promising option but, as discussed, such a design would entail additional challenges not factored into this study relating to the impact of sub-system shut downs on the connected AC system and offshore wind farms. In this scenario the level of connected wind capacity is below the loss of infeed limit for the GB network which is 1800MW [36] so the overall AC system should remain unaffected by DC grid sub system shut downs although there is still the potential for localised issues at the AC system landing points. For this scenario the number of shut down events was found to be around eight per year although this would increase for larger and more complex grids. The minimum breaker design option would have less impact on connected systems and provides only slightly reduced value for money.

Due to its high CAPEX and minimal additional benefits, the meshed grid option was found to be the least value for money. The bipole grid option by comparison has a high capital cost but significant benefits in terms of delivered energy and is therefore the best value for money under the worst case reliability scenarios and also compares favourably under the central case reliability scenario.

\section{B. Component Sensitivity Analysis}

To better understand the key drivers behind the reliability of offshore grids a sensitivity study is performed to look at the impact of individual components on overall reliability. Fig. 5 shows the results of a sensitivity study on the repair rates of individual component types for the multi-terminal grid option.

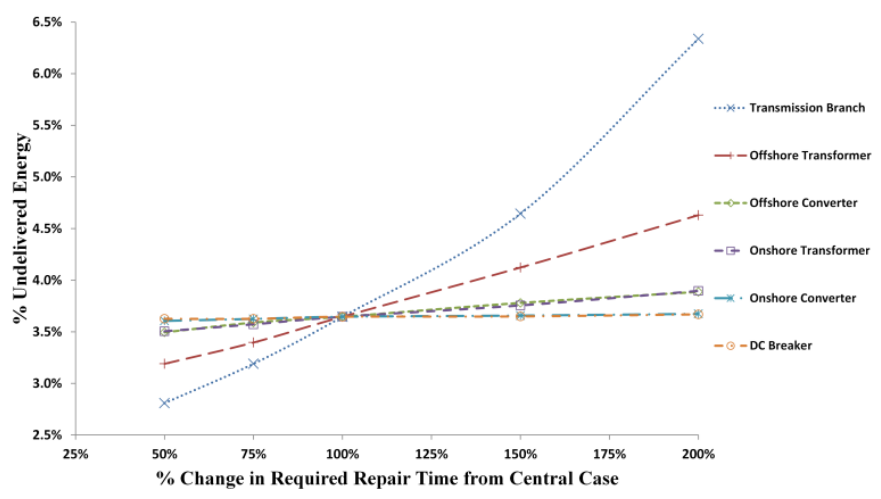

Fig. 5 - Component Sensitivity Study to Repair Rate - Multi-terminal Grid

The input parameters for component repair, both in terms of fixed delays and required repair times are altered incrementally between $50 \%$ and $200 \%$ of the central reliability scenario estimates for each component to show the impact on final levels of undelivered energy.

It is clear that overall grid reliability is highly sensitive to transmission branch failures in particular with changes in the repair rate of offshore transformers also having a large impact. A sensitivity study of the failure rate of individual components yields a similar result. Both transmission branch and offshore transformer faults could be described as being low probability, high impact events in that they are relatively rare yet can take a long time to repair if they do occur. The sensitivity study shows that offshore grids are particularly susceptible to variations in faults of this kind meaning that the overall performance of any grid option in a given 25 year lifespan is likely to be heavily influenced by how close the numbers and durations of repairs are to the mean expected values. This means that on a year to year basis the reliability performance is likely to fluctuate significantly around the mean expected figures derived from this study. 
This study helps point towards measures that could be implemented to mitigate these sensitivities and help de-risk offshore grid investment. It has been shown that using a grid topology, such as the bipole configuration, that allows partial power delivery in the event of single failure events can significantly reduce the influence of these otherwise high impact events. The study also highlights areas which the industry could look to improve upon in terms of minimising both the number of component failures and the length of downtime when failures do occur. Failures could be minimised by ensuring best practice design and installation procedures but also potentially through information campaigns to minimise external faults like anchor drags or trawling in offshore transmission corridors. The holding of spare components and investment in appropriate offshore repair vessels could also significantly reduce the lead time on repair of certain components but as ever the potential benefits of such measures must be weighed against the level of required investment.

\section{CONCLUSION}

This paper has presented a novel methodology for investigating the reliability of different offshore grid options which takes into account realistic constraints faced in the offshore environment. A number of case studies have been investigated for the connection of an offshore cluster of wind farms which compare HVDC grids using different technology options, varying protection strategies and differing levels of inherent system redundancy. It is found that there is clear value in having alternative transmission paths for power flow in the event of faults. However, the cost associated with implementing a meshed DC grid which is protected using DCCBs is restrictively high. Alternative protection methods can be delivered at better value so long as the impact on connected systems can be managed.

Offshore grid reliability is found to be highly sensitive to low probability, high impact failures such as transmission branch faults. The use of a bipole transmission configuration appears to be one way to mitigate this sensitivity which provides good value compared with the associated additional costs.

\section{ACKNOWLEDGEMENTS}

For data from the FINO project, we thank the BMU (Bundesministerium fuer Umwelt, Federal Ministry for the Environment, Nature Conservation and Nuclear Safety) and the PTJ (Projekttraeger Juelich, project executing organisation).

\section{REFERENCES}

[1] A. Zervos and C. Kjaer. (2009). Pure Power: Wind Energy Targets for 2020 and 2030. Available: http://www.ewea.org/

[2] The North Seas Countries' Offshore Grid Initiative, "NSCOGI 2013/2014 progress report," 2014.

[3] J. De Decker and P.Kreutzkamp. (2011). OffshoreGrid: Offshore Electricity Infrastructure in Europe. Available: http://www.offshoregrid.eu/

[4] D. Van Hertem and M. Ghandhari, "Multi-terminal VSC HVDC for the European supergrid: Obstacles," Renewable and Sustainable Energy Reviews, vol. 14, pp. 3156-3163, 2010.
[5] National Grid, "Ten Year Statement - Appendix E: Technology," 2013.

[6] C.-C. Liu, L. He, S. Finney, G. P. Adam, J.-B. Curis, O. Despouys, et al., "Preliminary Analysis of HVDC Networks for Off-Shore Wind Farms and Their Coordinated Protection," Twenties, Deliverable 5.1, 2011.

[7] Twenties, "Comparison of different network solutions in the North Sea offshore system," 2013.

[8] R. Hodges and R. Bryans, "Reliability Analysis of Electrical Systems for Offshore Wind," in 42nd ESReDA Seminar on Risk and Reliability for Wind Energy and other Renewable Sources, Glasgow, 2012.

[9] TNEI Services Ltd, "Irish-Scottish Links on Energy Study (ISLES): Route Development and Cost Estimation Report," 2012.

[10] K.R.W. Bell, L. Xu, and T. Houghton, "Considerations in design of an offshore network," presented at the Cigré Paris Session, paper C1-206, Paris, 2014.

[11] N. Ahmed, S. Norrga, H. P. Nee, A. Haider, D. Van Hertem, Z Lidong, et al., "HVDC SuperGrids with modular multilevel converters - The power transmission backbone of the future," in Systems, Signals and Devices (SSD), 2012 9th International MultiConference on, 2012, pp. 1-7.

[12] J. Hafner and B. Jacobson, "Proactive Hybrid HVDC Breakers - A key innovation for reliable HVDC grids," in The Electric Power System of the Future - Integrating Supergrids and Microgrids International Sysmposium, Bologna, 2011.

[13] R.Derakhshanfar, T.U.Jonsson, U.Steiger, and M.Habert, "Hybrid HVDC breaker - A solution for future HVDC system," presented at the Cigré Paris Session, paper B4-304, Paris, 2014.

[14] Twenties, "Feasibility tests of Direct Current Circuit Breaker prototype in DEMO3-DCGRID: breaking test demonstration," 2013.

[15] Cigré Working Group B4-52 "HVDC Grid Feasibility Study," 2013.

[16] D. Jovcic, D. van Hertem, K. Linden, J. P. Taisne, and W. Grieshaber, "Feasibility of DC transmission networks," in Innovative Smart Grid Technologies (ISGT Europe), 2011 2nd IEEE PES International Conference and Exhibition on, 2011, pp. $1-8$.

[17] M. M. C. Merlin, T. C. Green, P. D. Mitcheson, D. R. Trainer, R. Critchley, W. Crookes, et al., "The Alternate Arm Converter: A New Hybrid Multilevel Converter With DC-Fault Blocking Capability," Power Delivery, IEEE Transactions on, vol. 29, pp. 310-317, 2014.

[18] C. D. Barker, R. S. Whitehouse, A. G. Adamczyk, and M. Boden, "Designing fault tolerant HVDC networks with a limited need for HVDC circuit breaker operation," presented at the Cigré Paris Session, paper B4-112, Paris, 2014.

[19] C. MacIver and K. R. W. Bell, "Reliability Analysis of Design Options for Offshore HVDC Networks," presented at the Cigré Paris Session, paper B4-111, Paris, 2014.

[20] Bundesamt für Seeschifffahrt und Hydrographie (BSH). FINO Datenbank [Online]. Available: http://www.bsh.de/de/Meeresdaten/Projekte/FINO/index.jsp

[21] I. Dinwoodie, D. McMillan, M. Revie, I. Lazakis, and Y. Dalgic, "Development of a Combined Operational and Strategic Decision Support Model for Offshore Wind," Energy Procedia, vol. 35, pp. 157-166, 2013.

[22] TRADEWIND, "Integrating Wind: Developing Europe's Power Market for the Large Scale Integration of Wind Power - WP2.6 Equivalent Wind Power Curves," 2009.

[23] K. Linden, B. Jacobson, M. H. J. Bollen, and J. Lundquist, "Reliability study methodology for HVDC grids," presented at the Cigré Paris Session, paper B4-108, Paris, 2010.

[24] Sinclair Knight Merz, "Calculating Target Availability Figures for HVDC Interconnectors," ofgem, 2012.

ISLES (The Scottish Government. Irish-Scottish Links on Energy Study), "Technology Roadmap Report," 2012.

R. Billinton and W. Li, Reliability Assessment of Electrical Power Systems Using Monte Carlo Methods. New York: Plenum Press, 1994.

[27] P. Tavner, Offshore Wind Turbines: Reliability availability and maintenance vol. 13: IET Renewable Energy Series, 2012.

[28] T. Worzyk, Submarine power cables: design, installation, repair, environmental aspects: Springer, 2009. 
[29] Cigré Working Group B4.46, "Voltage Source Converter (VSC) HVDC for Power Transmission - Economic Aspects and Comparison with other AC and DC Technologies," Cigré, 2012.

[30] ENTSO-E, "Offshore Transmission Technology," 2011.

[31] I. Dinwoodie, O. V. Endrerud, M. Hofmann, R. Martin, and I. B. Sperstad, "Reference Cases for Verification of Operation and Maintenance Simulation Models for Offshore Wind Farms " Wind Engineering, In Press.

[32] D. S. Kirschen, K. R. W. Bell, D. P. Nedic, D. Jayaweera, and R. N. Allan, "Computing The Value of Security," IEE Proc. on Generation, Transmission and Distribution, vol. 150, pp. 673-678, Nov 2003.

[33] R. Rubinstein and D. P. Kroese, Simulation and the Monte Carlo Method, 2nd ed. New Jersey: John Wiley \& Sons, 2008.

[34] J. P. Kjaergaard, K. Sogaard, S. D. Mikkelsen, T. Pande-Rolfson, A. Strandem, B. Bergdahl, et al., "Bipolar operation of an HVDC VSC converter with an LCC converter," in HVDC and Power Electronic Systems for Overhead Line and Insulated Cable Applications Colloqium, San Francisco, 2012.

[35] UK Department of Energy \& Climate Change, "Investing in renewable technologies - CfD contract terms and strike prices," 2013.

[36] ofgem. (2011). National Electricity Transmission System Security and Quality of Supply Standard (NETS SQSS): Review of Infeed Losses (GSR007 as revised by GSR007-1). Available: https://www.ofgem.gov.uk/ofgem-publications/52793/gsr007decision-letter-final.pdf

\section{BIOGRAPHIES}

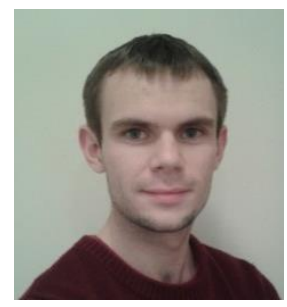

Callum MacIver received the M.Eng. degree in Electrical and Mechanical Engineering (Distinction) in 2010 from the University of Strathclyde and is currently working towards a Ph.D. as part of the university's Wind Energy Systems Centre for Doctoral Training. His research interests include the design and reliability of future offshore HVDC networks for the connection of wind power and the interconnection of regions.

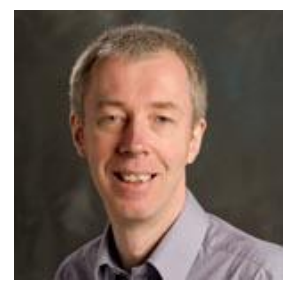

Keith Bell is the ScottishPower Professor of Smart Grids at the University of Strathclyde. He joined the University in 2005 having previously worked as an electrical engineering researcher in Bath, Manchester and Naples, and as a system development engineer in the electricity supply industry in Britain. He is a co-Director of the multi-disciplinary UK Energy Research Centre, an invited expert member of CIGRE Study Committee C1 on System Development and Economics and a member of the Council of the IET Power Academy, an initiative to promote electric power engineering as a graduate career in the UK. He is a Chartered Engineer and has advised the Scottish Government, the Republic of Ireland government, the Northern Ireland Executive, Ofgem and the UK Department of Energy and Climate Change on electrical energy and power systems issues.

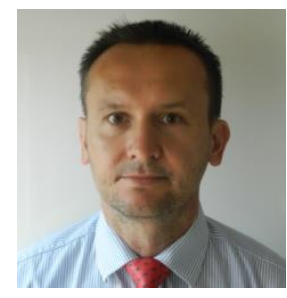

Duško Nedić is an Executive Consultant with Siemens Energy Management, SmartGrid Division. He joined Siemens in 2010, having previously worked as a consultant/transmission design engineer in Britain. He received his BSc degree from University of Novi Sad, Serbia, his MSc degree from University of Belgrade, Serbia and his Phd from UMIST, UK. His research interest is in power system security and reliability. 